\title{
TRÁFICO DE PESSOAS PARA FINS DE EXPLORAÇÃO SEXUAL NA FRONTEIRA BRASIL-VENEZUELA: DESAFIOS E FORMAS DE PREVENÇÃO E COMBATE AO ILÍCITO
}

\author{
Larissa de Alencar Mahon ${ }^{1}$
}

RESUMO: O presente artigo objetiva demonstrar de que forma os entraves criados por uma política migratória restritiva, aliados à falta de políticas públicas de integração social e às ausências estruturais locais para receber estes imigrantes, podem se relacionar com o aumento do número de casos de tráfico de seres humanos. Aponta-se os principais motivos para o crescimento do fluxo migratório venezuelano para o Brasil nos últimos cinco anos, as graves violações de direitos humanos sofridas pelos imigrantes, as principais rotas de tráfico para fins de exploração sexual na fronteira Brasil-venezuela, os meios de atuação das organizações criminosas, bem como as estratégias utilizadas no combate ao crime.

Palavras-chave: Política Migratória. Tráfico de pessoas. Violação de Direitos humanos.

ABSTRACT: This article aims to demonstrate how the obstacles created by a restrictive migratory policy, combined with the lack of public policies for social integration and the local structural absence to receive these immigrants, can be related to the increase in the number of cases of human trafficking. The main reasons for the growth of the Venezuelan migratory flow to Brazil in the last five years were pointed out, the serious human rights violations suffered by immigrants, the main trafficking routes for sexual exploitation on the Brazil-Venezuela border, the means of actions of criminal organizations, as well as the strategies used to fight crime.

Keywords: Migration Policy. Human trafficking. Violation of human rights.

\section{INTRODUÇÃO}

O direito de migrar existe desde a antiguidade, entretanto, com a globalização, os fluxos migratórios cresceram de forma vertiginosa, haja vista a expectativa de uma melhor condição de vida criada pelo desvanecimento das fronteiras e pela maior integração econômica entre as diferentes regiões geográficas.

Apesar da redução das barreiras físicas, tecnológicas e culturais, são inúmeros os desafios que os migrantes necessitam enfrentar para serem reconhecidos e aceitos na sociedade receptora e, muitas destas dificuldades se devem aos obstáculos criados pela legislação migratória de cada país, que acabam os impedindo de se regularizar documentalmente.

\footnotetext{
${ }^{\mathrm{I}}$ Mestranda em Direito das Relações Internacionais pela Universidad de La empresa em Montevideo, Uruguay; Pós- Graduação lato sensu em Direito Civil e Processual Civil pela Faculdade Maurício de Nassau, em convênio com a Escola de Magistratura de PE (2006-20o8);Pós- graduação lato sensu em Direito Público pela UNIDERP-MS (2007). Graduação pela faculdade de Direito de Olinda em 2005. Cargo atual: Analista Judiciária do TJPE desde 2oro. Assessora de magistrado.
} 
Além disso, há muita estigmatização em torno da imigração, que não raramente é associada ao aumento da criminalidade e ao terrorismo, acarretando comportamentos discriminatórios e xenofóbicos por parte da população local.

Desta forma, encontrando-se em uma posição de vulnerabilidade social, sem condições de retorno ao país de origem e, ainda, sem possibilidades de exercer um trabalho formal e em condições dignas, os imigrantes acabam se tornando vítimas das organizações criminosas para o tráfico humano, que os aprisiona e escraviza, violando a sua dignidade.

Não obstante o crime de tráfico de pessoas apresente diversas finalidades, o presente estudo se debruça sobre aquele praticado para fins de exploração sexual e, relativamente aos imigrantes venezuelanos na fronteira Brasil-Venezuela, que tem como porta de entrada o Estado de Roraima.

$\mathrm{O}$ artigo cuida, portanto, de traçar o perfil dos imigrantes que mais facilmente se tornam vítimas do tráfico e aponta os principais meios e rotas de que se valem os aliciadores no cometimento do ilícito.

Uma atenção especial é dada ao Protocolo de Palermo, por ter sido este o primeiro instrumento internacional de combate ao tráfico de pessoas que levou o Brasil a formular uma política Pública com o objetivo de prevenir e combater o crime, conhecida como Plano Nacional de Enfrentamento ao Tráfico de Pessoas,

Durante o desenvolvimento deste escrito, demonstramos como tem sido a gestão do fluxo migratório venezuelano no Estado de Roraima, com o objetivo de discutir a forma pela qual os obstáculos enfrentados pelos imigrantes podem ser minimizados, tanto pela uniformização das leis quanto por meio da criação de políticas públicas eficazes, que respeitem os seus direitos humanos e busquem integrá-los na comunidade local.

Agindo desta maneira, acreditamos que as organizações criminosas para o tráfico terão mais dificuldades de captar integrantes e, aos poucos, as atividades ilegais irão reduzir.

Cumpre destacar, ademais, que pelo fato de ser a transnacionalidade uma característica intrínseca ao comércio internacional de seres humanos, seu enfrentamento mobiliza organismos internacionais, que devem cooperar entre si com o objetivo de combater a criminalidade organizada.

\section{Migrações internacionais e Globalização}

Do latim migratio, migração significa deslocamento do indivíduo dentro de um espaço geográfico de forma temporária ou permanente e, em se tratando de migrações internacionais, deslocamento de um Estado para outro.

Conquanto as migrações existam desde a antiguidade, atualmente, elas representam um espelho das assimetrias socioeconômicas vigentes em nível planetário, isto é, enquanto os fluxos migratórios antigamente eram, em regra, forçados, no mundo contemporâneo, tornaram-se fruto de uma escolha consciente dos migrantes que, diante de uma maior integração econômica entre os países, passaram a buscar por melhores condições de vida nas regiões geográficas mais desenvolvidas.

Em verdade, o processo de migração internacional pode ser desencadeado por diversos fatores, como é o caso dos desastres ambientais, guerras, perseguições políticas, étnicas ou culturais entre outros, contudo, o principal motivo é o econômico, no qual as 
pessoas deixam seu país de origem visando à obtenção de emprego e melhores perspectivas de vida em outras nações.

Tanto é verdade, que pesquisas refletem que os países destinos das migrações internacionais são, em regra, os países desenvolvidos e industrializados, onde os migrantes acreditam que encontrarão uma boa oportunidade de trabalho, refletindo, assim, as assimetrias socioeconômicas existentes no mundo.

Indubitável também que outros fatores que contribuem para a emigração de um país são a distância geográfica e cultural do país de destino, bem como as políticas migratórias deste.

Uma das causas apontadas para explicar o aumento do número de migrantes induzidos por razões econômicas é a globalização, fenômeno que reduziu as barreiras físicas, tecnológicas e culturais ao movimento internacional de bens e serviços, ideias, capitais e, sobretudo, de indivíduos.

É bem verdade, por exemplo, que hoje em dia as pessoas encontram muito mais facilidade para atravessar as fronteiras internacionais em razão de um desvanecimento desses limites tradicionais.

Essa maior permeabilidade das fronteiras, contudo, acaba por causar problemas de ordem política e social, dentre eles a questão da migração de trabalhadores.

Quanto à questão, vale ressaltar que muito embora haja uma redução do controle de território por parte do Estado, em razão da atuação das forças dos mercados internacionais e em decorrência dos novos meios de comunicação, este ainda retém um papel central que garante uma grande dimensão de controle territorial, qual seja: a regulação das populações.

Diante desta análise, válido asseverar que o Estado democrático ainda é possuidor de um território e tem o papel de regular a sua população, o que lhe confere uma legitimidade definida internacionalmente a que nenhuma outra agência poderia ter, no que diz respeito ao que ele pode dizer para aquela população (HIRST; THOMPSON, 2002).

Conclui-se, portanto, que as fronteiras se desvanecem, mas só tem acesso ao Estado territorial aquele que é autorizado previamente por sua administração pública.

Ou seja, não basta a existência das variantes econômicas e sociais para que o movimento migratório se efetive, sendo necessário também que o migrante se submeta ao crivo da soberania do Estado de acolhida, que é quem decide quem entre e quem permanece no local.

Formas de Acesso ao país de acolhida: migrações clandestinas, regulares, forçadas, voluntárias e suas respectivas formas de proteção internacional:

A intensificação dos fluxos migratórios internacionais das últimas décadas provocou o aumento do número de países orientados a regulamentar e até reduzir a imigração. Os argumentos alegados não são novos, dentre eles: o medo de uma invasão migratória, os riscos de desemprego para os trabalhadores autóctones, a perda da identidade nacional e, até, o espectro do terrorismo.

Há uma evidente estigmatização dos migrantes como responsáveis pelas crises sociais dos países de acolhida, o que acaba fomentando o aumento da violência e xenofobia contra os estrangeiros e a consequente falta de proteção aos mesmos, notadamente aos 
mais vulneráveis, isto é, aqueles que não conseguem atender às rígidas exigências legais do país de destino e lá permanecem de forma clandestina.

Tudo isso levou a um aumento da migração irregular, que se relaciona diretamente com as políticas migratórias restritivas.

Quando é difícil atravessar uma fronteira legalmente, e existe uma necessidade impelente de fazê-lo, tentam de fato a migração não autorizada. Quando as pessoas estão despojadas de seus direitos, como os migrantes em situação irregular, é fácil explorá-los e maltratá-los, e, ao mesmo tempo, obter benefícios econômicos à custa delas. (apud MARINUCCI; MILESI, 2004).

A migração ilegal ou irregular constitui de longe a forma de migração que registrou o mais rápido crescimento nos últimos dez anos.

Afirma Bravo que é preciso estarmos atentos para o fato de que o simples reforço dos controles migratórios nos locais de maior atração para imigrantes pode, na realidade, deixar indivíduos de regiões periféricas ainda mais vulneráveis, uma vez que, em sendo os destinos proibidos, os traficantes de pessoas expandem seus poderes predatórios, pois consolidam-se como a única via de acesso, embora ilícita, a esses locais (apud GALINDO, 2015).

Assim, medidas para a eliminação da exploração humana ou redução do número de imigrantes devem efetivamente contemplar o caráter sistêmico do combate a vulnerabilidades.

Isto é, deve-se buscar reduzir vulnerabilidades sociais pelo reforço de garantias públicas de saúde e educação, reduzindo, com isso, as desigualdades existentes, sendo importante também documentar os imigrantes.

Isso porque, consequência direta da ilegalidade é o poder, ou melhor, direito soberano do Estado de excluir, a qualquer tempo, o imigrante indocumentado do seu território. Tanto é assim que é fato incontroverso que migrantes indocumentados tendem a evitar qualquer contato com as autoridades estatais, pelo risco de deportação inerente a esse contato. Com isso, perdem também o direito de reivindicar os seus direitos, uma vez que isso não se faz possível sem a intervenção de autoridades estatais. (GALINDO, 2015).

E preciso termos em vista que mesmo o migrante regular/documentado, apesar de poder gozar de certos direitos básicos no país de acolhida, ainda assim tem o seu direito à cidadania bastante restringido, uma vez que não pode exercer direitos políticos e também pode ser deportado e certas circunstâncias. Será, pois, sempre um "estrangeiro".

As migrações podem ser classificadas ainda como voluntárias ou forçadas. Aquelas motivadas por fatores econômicos são, em regra, consideradas voluntárias, sendo entendidas como aquelas nas quais o migrante planeja ir para outra região em busca de melhores condições de vida, mas pode voltar ao seu país de origem, caso deseje, sem que isso implique problemas à sua segurança pessoal.

Ao contrário, as migrações forçadas ocorrem quando as situações vividas pelo migrante são tão perigosas e intoleráveis, como aquelas motivadas por questões religiosas, guerra ou fatores ambientais, que o mesmo decide cruzar as fronteiras em busca de segurança em outro país, não podendo retornar ao país de origem sem prejuízos à sua segurança.

Esta distinção entre formas de migração acarreta mecanismos de proteção diferenciados, já que aos migrantes forçados, conceito no qual se enquadram os refugiados 
ou solicitantes de asilo, passam a ter assistência específica pela legislação internacional, ao passo que aos migrantes espontâneos, como são considerados os migrantes econômicos, por exemplo, contam com uma proteção específica bastante precária.

Desta forma, podemos dizer que não há nenhum sistema de proteção ou tratado internacional que garanta a proteção dos migrantes espontâneos, uma vez que não obstante a existência do Pacto Global para migrações, adotado em 2018, não foi este dotado de caráter vinculante, deixando estas pessoas desamparadas e dependentes da legislação de cada Estado.

O Pacto Global foi acordado pela primeira vez pelos Estados-membros da ONU, assinado na ocasião por I64 países, dentre os quais o Brasil, com o objetivo de melhor gerenciar a migração internacional, enfrentar seus desafios e fortalecer os direitos dos migrantes, contribuindo para o desenvolvimento sustentável.

O seu texto está profundamente enraizado naCarta das Nações Unidas e na Declaração Universal dos Direitos Humanos. Trata-se de um grande projeto de cooperação internacional, já que reconhece que a migração é uma fonte de prosperidade, inovação e desenvolvimento sustentável em um mundo moderno e globalizado.

Tal pacto reconhece que nenhum Estado pode abordar a migração sozinho e defende sua soberania e suas obrigações sob a lei internacional. Ocorre que apresenta uma estrutura cooperativa não juridicamente vinculante que se baseia nos compromissos acordados pelos próprios Estados.

Apesar disso, há Estados que não o apoiam, como é o caso do Brasil, que em janeiro de 2019, foi retirado do pacto pelo presidente Jair Bolsonaro e o atual ministro das Relações Exteriores, Ernesto Araújo, com a justificativa de defesa da soberania do País para discutir acerca dos migrantes, o que não se mostra uma justificativa plausível, porquanto o pacto não desrespeita a soberania dos estados, apenas cria um espaço em que os países compartilhem informações e troquem experiências relacionadas às políticas nacionais migratórias, a fim de que possam criar normas e avaliar melhor a questão.

Em razão dessa falta de uniformização, os direitos humanos têm dificuldades para legitimar políticas com relação às migrações internacionais, pois os migrantes que se deslocarem voluntariamente, ficam sob a responsabilidade de seus Estados e à mercê da legislação local do país que os acolheu, longe de um direito universalmente reconhecido, o que lhes confere uma situação de desvantagem em relação aos refugiados.

Ante essa ausência ou insuficiência normativa, há uma tendência de se buscar enquadrar todas as situações de migrantes nos poucos institutos legais internacionais existentes, o que impossibilita uma utilização mais criteriosa das distinções entre os migrantes, além de impedir o desenvolvimento de novos mecanismos de proteção que abarquem outras categorias.

Exemplo disso é a utilização indiscriminada do instituto do refúgio por pessoas não elencadas pelo Direito internacional para receber o tipo de proteção que o instituto confere, enfraquecendo-o. 


\section{Violação dos direitos humanos dos imigrantes e breve análise da política migratória no Brasil}

Os direitos humanos são direitos naturais e básicos garantidos a todo e qualquer indivíduo, devendo ser estendidos a pessoas de todas as nações, independentemente de sua classe social, etnia, gênero, nacionalidade ou posicionamento político.

Tais direitos não derivam do fato de uma pessoa pertencer a um determinado Estado ou Nação, mas de sua condição de pessoa, cuja dignidade merece proteção onde quer que esteja.

Ademais, o direito de se sentir parte de uma nação, é um direito básico ligado diretamente à cidadania e ao sentimento de dignidade, de modo que os obstáculos criados a essa inclusão, constitui grave violação aos direitos humanos do imigrante.

O que se vê hoje em dia, entretanto, é que, mesmo havendo legislação protetora de direitos humanos, a sua efetivação encontra barreiras nos interesses políticos, econômicos e demográficos dos Estados soberanos, que continuam a colocar os "imigrantes de fato" em situações de vulnerabilidade, com marginalizações e até criminalizações, os tratando como um problema de segurança pública e de polícia, quando deveriam ser tratados como sujeitos de direitos.

Isso ocorre porque, como já foi dito, a soberania dos Estados permanece inatacável e não há organismo internacional que possa exercer qualquer punição efetiva aqueles que violam direitos inerentes à condição humana, especialmente quando as vítimas não são da nacionalidade do Estado violador.

Assim, talvez mais que uma evolução legislativa, haja necessidade de uma evolução cultural, de forma que passemos a enxergar o imigrante não como um inimigo e sim como um ser humano igual a qualquer outro e que, em razão disso, precisa ter os seus direitos fundamentais protegidos.

É preciso atentar também para o fato de que a inclusão e melhor recepção desses imigrantes não apenas os beneficiará, por razões humanitárias, como também contribuirá para o desenvolvimento do Estado-receptor, haja vista a troca de visões decorrentes da diversidade cultural, o reforço ao mercado laboral entre outros benefícios.

Não é essa a visão que prevalece na prática, infelizmente, conforme veremos ao analisar as restrições criadas ao acesso à cidadania por parte dos imigrantes.

Como cidadania, podemos conceituar a igualdade perante a lei e igualdade de acesso aos direitos, contudo, não há nenhuma identidade entre imigrantes e cidadãos "nacionais". O fato de os estrangeiros gozarem de um maior número de direitos hoje, não modifica a natureza da cidadania. O estrangeiro continua numa situação precária em relação ao cidadão.

Somente os cidadãos gozam de um direito incondicional de permanência e residência no território e podem planejar suas vidas de acordo com esses direitos. A entrada e a residência de não-cidadãos nunca são incondicionais.

Alguns não-cidadãos, os que entraram clandestinamente, por exemplo, ou pessoas no final do seu período de residência legal, não têm esses direitos. 
Deste modo, a cidadania tratada como atributo exclusivo do nacional exclui o imigrante, que é tratado como estranho e desconhecido, além de portador de uma cultura e valores diferentes daqueles do cidadão nacional do Estado-nação.

A sociedade, por sua vez, sendo estimulada pelo seu Estado a tal entendimento individualista, revela-se amedrontada e preconceituosa, impossibilitando a aceitação do outro no meio social, o que constitui patente violação aos direitos humanos dessas pessoas.

De acordo com o sociólogo Zygmunt Bauman, os imigrantes:

[...]nos tornam conscientes e nos lembram daquilo o que preferiríamos esquecer ou, melhor ainda, fazer de conta que não existe: forças globais, distantes, ocasionalmente mencionadas, mas em geral despercebidas, intangíveis, obscuras, misteriosas e difíceis de imaginar, poderosas o suficiente para interferir também em nossas vidas, enquanto desconsideram e ignoram nossas próprias preferências".

E mais:

[...] Esses nômades - não por escolha, mas por veredicto de um destino cruel- nos lembram, de modo irritante, exasperante e aterrador, a (incurável?) vulnerabilidade de nossa própria posição e a endêmica fragilidade de nosso bemestar arduamente conquistado. (BAUMAN, 2017).

Levadas tais considerações em conta, é certo que garantir a participação política aqui entendida em sentido lato sensu, como o direito de ser reconhecido como sujeito apto a participar da vida pública, apenas aos nacionais, constitui um dos bastões a que os EstadosNação se negam a renunciar.

Sendo assim, resta evidenciado que a cidadania não pode mais ser estudada do ponto de vista estrito, apenas como o gozo de exercer direitos políticos, mas sim como o direito a ter direitos; direito a pertencer a uma comunidade organizada.

Hannah Arendt chegou à seguinte conclusão em relação à matéria: "O homem pode perder todos os chamados Direitos do homem sem perder sua qualidade essencial de homem, sua dignidade humana. Só a perda da própria comunidade é que o expulsa da humanidade". (apud NASCIMENTO, 2012).

Apesar de não se pode especificar uma data para a criação dos Direitos Humanos, pode-se dizer que foram reconhecidos internacionalmente, tão somente, com a Declaração Universal dos Direitos Humanos, adotada pela Organização das Nações Unidas em io de dezembro de 1948. Tal declaração é considerada um marco para o Direito internacional, por estabelecer princípios e valores universais a serem respeitados pelos Estados.

A declaração Universal dos Direitos Humanos é composta de trinta artigos, que definem os direitos essenciais, iguais e inalienáveis de todos os seres humanos como fundamento de liberdade, justiça e da paz no mundo. Proclama o ideal comum, a ser atingido por todos os povos e todas as nações (ANNONI, 2013).

O movimento internacional dos direitos humanos, tinha por lema promover a proteção de qualquer ser humano em qualquer lugar, o que resultou por conferir duas características essenciais: a universalidade e a indivisibilidade.

Apesar da tentativa de universalizar os direitos humanos por meio da criação de tratados e leis internacionais, fato é que a proteção destes direitos não passou de mera utopia sem efetividade na prática, haja vista os muitos outros fatores envolvidos na adoção, pelos governos, desses documentos internacionais, tais como o multiculturalismo, 
já que, atualmente, são reconhecidos quatro regimes internacionais de aplicabilidade dos direitos humanos, ou seja, europeu, interamericano, africano e asiático, cada qual com suas peculiaridades locais.

Exemplo dessa falta de uniformidade quanto ao âmbito espacial de validade das normas de direito internacional dos Direitos Humanos é o caso do Pacto Internacional de Direitos Civis e políticos da ONU (1996), sendo este válido para todos os continentes, e, por outro lado, a Convenção Americana de Direitos Humanos, cuja validade se limita ao território americano.

Ademais, em paralelo aos textos de alcance geral, surgiram textos de proteção aos direitos humanos de alcance regional.

Indubitável que os direitos humanos dos migrantes dependem das políticas migratórias nacionais, pois são elas que determinam os direitos que os migrantes gozam na prática.

Não raro a soberania é invocada para justificar atropelos de ordem legislativa ou administrativa aos direitos dos migrantes; mas, o certo é que não deve haver contradição entre soberania e direitos humanos.

Ademais, o Direito Internacional determina que os direitos humanos estão acima dos interesses nacionais e da Soberania Estatal e a proteção deles deveria ser mais importante que as fronteiras.

Sendo assim, faz-se imprescindível investir na discussão de possibilidades para encontrar um equilíbrio entre pontos de vista não só culturais, mas também políticos quanto ao exercício dos direitos humanos a fim de que a violência e a desumanidade não sejam aceitas como sintomas naturais da sociedade.

\section{O caso específico do êxodo venezuelano no Brasil: Legislação aplicável e desafios encontrados pelos imigrantes:}

Diante do cenário de crise econômica e política na Venezuela, que vem crescendo desde meados de 2015, após o presidente Nicolás Maduro perder as eleições parlamentares no país, parte da população venezuelana começou a emigrar em maiores números para alguns países da América Latina, principalmente Colômbia e Brasil.

Pressões internacionais diversas acrescentadas às crises internas do modelo político que vigorou neste país desde o final da década de 1990 culminaram em crises econômicas, sociais e de abastecimento de alimentos.

Instaurou-se, a partir de então, um contexto de insegurança no país, acarretando um temor generalizado na população, que, por sua vez, passou a conviver com uma escassez de suprimentos básicos, hiperinflação e desemprego, o que acabou por gerar inúmeros problemas humanitários.

Devido às constantes violações aos direitos humanos por parte da Venezuela, que foram, inclusive, objeto de condenação por sentenças da Corte Interamericana de Direitos humanos e, ainda, por ter o referido país violado o Protocolo de Assunção sobre compromisso com a promoção e proteção dos direitos humanos por meio da denúncia à Convenção Americana dos Direitos Humanos, teve a Venezuela suspensos os seus direitos de Estado parte do MERCOSUL. 
Apesar disso, os cidadãos venezuelanos ainda podem ser beneficiados, em algumas medidas, pelo esquema de integração do bloco.

Fato inegável é que, em decorrência dessa grave crise humanitária, um intenso fluxo migratório vindo da Venezuela foi inaugurado, afetando especialmente a América Latina, com destaque para a Argentina e o Brasil.

Estudos demonstram que a maior parte desses migrantes se desloca pela via terrestre e não tem um bom poder aquisitivo, tendo saído do país de origem às pressas, ou seja, sem qualquer tipo de regularização migratória como vistos ou autorização de residência prévios, havendo até mesmo aqueles que deixam o país sem portar documentos de identificação (COSTA, 2017).

Ainda com relação ao perfil desses imigrantes, há um predomínio daqueles que estão em idade produtiva (20-39 anos), solteiros, além da maioria deles possuir qualificação profissional e ensino médio completo. Poucos dominam outro idioma além do espanhol e os que conseguem emprego dificilmente ganham mais que or salário-mínimo de remuneração, trabalhando em condições precárias.

Na América Latina, a Declaração de Cartagena de 1984 ampliou o conceito para abarcar toda pessoa que estivesse fugindo de situação generalizada de violência ou violação dos direitos humanos. Diante de tal inovação, muitos estudiosos passaram a entender que os imigrantes venezuelanos enquadraram-se no conceito de refugiado, mesmo quando tenham migrado por motivos econômicos, face a situação de crise e de violação dos direitos humanos pela qual está passando a Venezuela.

Todavia, por tal enquadramento não ser ainda um consenso entre os autores, outras formas de proteção e regularização migratória devem ser implementadas para atender ao fluxo migratório Venezuelano.

Não obstante tais considerações, em junho de 2019, o CONARE reconheceu, tendo como base a definição ampliada de refúgio, a situação de grave e generalizada violação de direitos humanos na Venezuela.

A partir da decisão, passou-se a adotar um procedimento simplificado no processo de refúgio para venezuelanos, de maneira que até o final de janeiro de 2020, o Brasil já havia reconhecido mais de 17 mil venezuelanos como refugiados.

Somente a título explicativo, o CONARE (Comitê Nacional para refugiados), foi criado pelo Estatuto dos refugiados- Lei 9.474/97, com a atribuição de tomar decisões relativas a refúgio. Trata-se de um órgão que se utiliza de critérios jurídicos e humanitários para deferir os pedidos de refúgio. Vale dizer também que o Acnur está sempre autorizado a participar das reuniões do Conare, com voz, entretanto, sem direito a voto.

O que se observa, na realidade, é que, apesar das promessas constantes nas declarações firmadas, os Venezuelanos ainda encontram muitos problemas para ingressar e se regularizar nos países latino-americanos, o que se dá tanto pelo fechamento de fronteiras como pela exigência de documentos que eles, em regra, não possuem por haverem emigrado às pressas e em situação de extrema vulnerabilidade.

Podemos dizer que ainda para aqueles poucos que conseguem se regularizar no país de acolhida, não existem boas políticas públicas implementadas que o permitam integrar-se completamente à sociedade, fazendo com que sejam vítimas constantes de preconceitos e exclusão. 
No caso específico do Brasil, cumpre afirmar que a maior parte dos imigrantes venezuelanos ingressa no país, por via terrestre, na cidade de Pacaraima - Estado de Roraima - que faz fronteira com a Venezuela.

A travessia pela fronteira realizada pelos venezuelanos muitas vezes é bem complexa, pois, muitos por não terem como custear as passagens de ônibus ou táxis, optam por fazê-la caminhando, percorrendo mais de 200 quilômetros que separam a cidade de Pacaraima na fronteira e a capital Boa Vista, levando dias para a chegada.

O Brasil não aplica o Acordo de residência do MERCOSUL para lidar com o fluxo migratório venezuelano, fato que dificultou muito a regularização destes migrantes do ano de 2015 a início de 2017, quando a única solução por eles encontrada foi solicitar o refúgio.

Ao invés de aplicar o acordo supracitado, o Brasil preferiu adotar o critério da reciprocidade, excluindo, portanto a Venezuela, em razão da sua suspensão do bloco regional, tratando os imigrantes venezuelanos como migrantes de terceiros Estados, o que prejudicou demasiadamente, o fomento da cidadania regional e das normas sobre a livre circulação de pessoas, desconsiderando o fato de que a Venezuela ainda integra o MERCOSUL e o de que os países do bloco se comprometeram a minimizar os impactos negativos da suspensão para os cidadãos venezuelanos (COSTA, 2017).

Tão somente em março de 2017, o Brasil editou a Resolução no 126/2017 do Conselho Nacional de imigração, com vigência por I ano, passando então a conceder residência temporária por 2 anos para os imigrantes que ingressassem no país pelas vias terrestres e fossem nacionais de país fronteiriço. Ocorre que dita resolução não abarcava boa parte dos imigrantes, pois cobrava taxa e não atingia aqueles que chagavam ao país pelas vias aéreas.

Devido a isso, foi publicada a Portaria Interministerial no 09/2018 pelo Ministério da Justiça e segurança pública e Ministério das relações exteriores, que é aplicada aos imigrantes venezuelanos até os dias de hoje.

Dita portaria passou a conceder autorização de residência temporária por 2 anos aos venezuelanos (de uma forma geral e não só os que ingressavam pelas vias terrestres) , a qual pode ser convertida em permanente, desde que preenchidos certos requisitos, como a apresentação de documentos que, como já foi dito no decorrer deste trabalho, muitas vezes impossibilitam os imigrantes de regularizarem-se, tornando-os mais vulneráveis à exploração e ao tráfico internacional.

Ressalte-se ainda, que aPortaria confere menor segurança jurídica que o acordo de residência, pois, por não ter status de lei, está sujeita a modificações e revogações de forma bem mais simplificada para o governo.

Por fim, em novembro de 2017, entrou em vigor a nova lei de migração, no 13.445/2017, que passou a tratar a migração pela ótica dos Direitos Humanos, substituindo o antigo Estatuto do Estrangeiro (lei 6815/198o). Essa lei trouxe um avanço significativo, na medida em que proibiu a criminalização da migração, previu o repúdio à xenofobia e outras formas de discriminação e garantiu o acesso a um conjunto de direitos fundamentais em igualdade de condições com cidadãos nacionais.

O que se percebe, no entanto, é que embora essa lei adote uma postura mais humanitária quanto à imigração, ainda falha muito no estabelecimento de diretrizes e 
políticas públicas para integração do imigrante, necessitando, pois, de alguns avanços relativos à garantia de direitos e atendimento mais humanizado a estas pessoas.

Assim, a nova lei de migração, ainda que tenha adotado um viés mais humanitário para a acolhida dos venezuelanos, não mudou radicalmente a capacidade institucional de resposta das autoridades.

O Brasil ainda se encontra em uma fase de resposta humanitária no atendimento a esse fluxo migratório, necessitando, porém, desenvolver mais políticas de integração dos venezuelanos ao país. Diante dessa realidade, não há dúvidas de que se deve buscar soluções para a crise migratória, sendo válido destacar que a solução não deve se limitar a impedir a entrada de Venezuelanos no Brasil, o que contraria a Constituição Federal de 1988.

Para finalizar, devemos ter sempre em vista que, não obstante haja uma sobrecarga dos serviços públicos e impactos à economia, a entrada de migrantes no país não traz somente prejuízos, mas também méritos à economia local, já que há um reforço na mão de obra, além de que essas pessoas consomem e utilizam serviços, contribuindo para o movimento da economia.

Além disso, as políticas migratórias restritivas devem deixar de tratar a migração como um problema e parar de focar na irregularidade do migrante, passando, portanto, a enxergá-la como resultante dos processos sociais, crescentemente transnacionais. As migrações devem ser vistas como o exercício do direito de liberdade e não como meio de resistência ou exploração de imigrantes.

Tráfico de pessoas: conceituação e análise do crime sob a ótica do Princípio da Dignidade da pessoa humana

O Protocolo de Palermo, por sua vez, em seu artigo $3^{\circ}$, "a" traz a seguinte definição para o tráfico de pessoas:

"Significa o recrutamento, o transporte, a transferência, o alojamento ou o acolhimento de pessoas, recorrendo à ameaça ou uso da força ou a outras formas de coação, ao rapto, à fraude, ao engano, ao abuso de autoridade ou à situação de vulnerabilidade ou à entrega ou aceitação de pagamentos ou benefícios para obter o consentimento de uma pessoa que tenha autoridade sobre outra para fins de exploração. A exploração incluirá, no mínimo, a exploração da prostituição de outrem ou outras formas de exploração sexual, o trabalho ou serviços forçados, escravatura ou práticas similares à escravatura, a servidão ou a remoção de órgãos". (BRASIL, 2004).

Como se vê, pelas definições acima, diversas podem ser as finalidades do crime de tráfico de pessoas quais sejam: tráfico para fins de exploração sexual; para fins de remoção de órgãos, para trabalho escravo, matrimônio servil entre outras formas de violação de direitos humanos.

Seja qual for a finalidade, o crime de tráfico de pessoas é uma das facetas mais lucrativas da organização criminosa, principalmente o praticado para fins de exploração sexual (PINTO et al, 2017)

Nesse tipo de crime, os traficantes se utilizam de um controle disciplinar sobre as vítimas por meio do aliciamento, ameaça, coerção ou da dívida servil para forçá-las a trabalhar em circunstâncias abusivas, privando-as de sua vontade. 
Nesse ponto, é possível afirmar que se trata de um crime que viola gravemente os direitos consagrados na Declaração Universal dos Direitos do Homem, tais como: o direito à liberdade, à igualdade e dignidade, à segurança pessoal e direito à vida e ao direito de não ser mantido em escravidão ou servidão.

Não há dúvidas de que o crime de tráfico humano, dada a humilhação, desrespeito e desonra a que são submetidas as vítimas, viola profundamente a dignidade humana, vez que claramente invade a privacidade e interfere na vontade daqueles que são enganados e/ou forçados a praticar algo contra a vontade.

A dignidade humana é arrolada como princípio fundamental do Estado democrático de Direito na Constituição Federal de 1988, em seu art. Io, III, o que torna o indivíduo a verdadeira razão de ser do Estado e os governantes, tão somente seus representantes e não seus senhores.

Para a Carta maior Brasileira, portanto, a dignidade humana, ao lado do exercício da cidadania, da liberdade de empreender e escolher o seu próprio destino, da valorização do direito do trabalhador e do exercício pleno das liberdades políticas são princípios fundamentais que andam lado a lado, constituindo a essência do Estado democrático de Direito.

Apesar de termos consciência da importância de preservar a dignidade humana, como forma de afastar os seres humanos da condição de objetos à disposição de interesses alheios, sabemos também que um dos grandes desafios da modernidade é como efetivar os direitos humanos, uma vez que a Declaração universal de Direitos humanos não consiste em um tratado internacional e sim numa declaração, havendo, por isso, discussões doutrinárias acerca da sua força vinculante.

Para que consideram a referida declaração de direitos como um conjunto de normas, ainda não vinculantes, mas que busca orientar a ação dos Estados a fim de que, futuramente, passem a ter força vinculante, entendem também que há uma barreira para efetivação dos direitos humanos não apenas na comunidade internacional, como também nos próprios Estados, seja por suas legislações próprias, seja pela falta de comprometimento com a sua eficácia.

A partir deste entendimento, ressaltamos a importância da cooperação internacional entre os Estados para fins de repressão de condutas criminosas que violem dos direitos humanos.

A cooperação internacional deve ser entendida como o ato de mútua ajuda entre dois Estados para a finalidade de um objetivo comum, que pode ser das mais diversas espécies, dentre as quais: políticas, culturais, estratégicas humanitárias e econômicas

No que diz respeito às causas motivadoras do crime de tráfico de pessoas, diga-se que decorrem de uma multiplicidade de fatores, dentre eles: as desigualdades sociais, falta de possibilidades de uma vida melhor, falta de condições de saúde e educação, pobreza entre outras.

Todas estas vulnerabilidades sociais acabam por transformar a vítima em mercadoria, vez que se deixam levar, com maior frequência, a promessas enganosas de uma vida melhor.

A instabilidade política, econômica e civil em regiões de conflito também pode ser apontada como uma causa que favorece o tráfico humano, afinal, diante da violência e da incerteza das pessoas quanto ao futuro, tornam-se vítimas fáceis de "oportunidades de 
emprego enganosas", às quais aceitam de pronto em busca de uma vida melhor. A corrupção de servidores públicos e a deficiência das leis também assumem um papel importante no favorecimento desse tipo de crime.

É bem verdade que está o crime de tráfico diretamente relacionado com a atividade migratória, haja vista que, aproveitando-se dos impulsos humanos do migrante, os traficantes fazem ofertas que nunca se realizarão e além disso, transformam os obstáculos criados pelos governos para legalização destas pessoas em lucro próprio, já que passam a explorá-las e escravizá-las, deixando-as sem opção de escolha.

Destaque-se que os migrantes clandestinos tornam-se os principais alvos das organizações criminosas, uma vez que, por medo de serem deportados para o país de origem, não procuram as autoridades responsáveis e terminam colaborando com a perpetuação da atividade criminosa.

Relativamente aos imigrantes venezuelanos, o Relatório do UNODC- Escritório da ONU sobre drogas e crimes realizado no ano de 2018 , destacou que a maioria das vítimas do tráfico humano (72\%) é composta por mulheres e meninas, que são traficadas para casamento ou escravidão sexual, enquanto os homens e meninos são mais vítimas do trabalho forçado, apenas ı\% deles são explorados sexualmente. O mesmo relatório afirmou que I/3 destas vítimas são crianças.

No Brasil, algumas modificações legislativas foram operadas no Código Penal após a ratificação, pelo país, do Protocolo de Palermo. Primeiramente, no código penal de I940, só se punia o tráfico de mulheres e para o exercício de prostituição.

Com a lei II.106/2005, passou-se a considerar vítimas de tráfico tanto o homem como a mulher, mas a atividade também se restringia à prostituição, o que só mudou com a lei n. 12.015/2009, que passou a incriminar o tráfico internacional de pessoas para fins de exploração sexual e não somente para fins de prostituição. dispunha:

Este crime passou a ser previsto no art. 23I da legislação penal pária, que assim

"Art. 231- Promover ou facilitar a entrada, no território nacional, de alguém que nele venha a exercer prostituição ou outra forma de exploração sexual, ou a saída de alguém que vá exercê-la no estrangeiro. Pena: reclusão de 3 a 8 anos”.

Fazendo uma comparação entre este dispositivo e o Protocolo de Palermo, observa-se que a questão do consentimento da vítima é ignorada na legislação brasileira, ao passo que é prevista no Protocolo (art. 3, "d"). Além disso, o Protocolo prevê várias finalidades para o tráfico, ao passo que o código penal brasileiro só prevê o tráfico de pessoas para fins de exploração sexual.

Ocorre que em 06.10.2016, foi sancionada a lei 13.344 (nova lei sobre o tráfico de pessoas), considerada o marco legal de prevenção, repressão e punição. Essa lei alterou o Código penal brasileiro para adequar o tipo penal ao Protocolo de Palermo (FREIRE, 2017). Com ela foram revogados os arts. 231 e 231-A do Código penal brasileiro.

Com ela, passaram a ser punidas outras formas de exploração e não só a sexual. $O$ art. 13 da referida lei acrescentou o art. 149-A do código penal, que passou a conceituar o tráfico de pessoas de uma maneira bem mais ampla, prevendo, além da exploração sexual, várias outras finalidades para o crime de tráfico de pessoas.

Sendo assim, não há dúvidas de que a lei 13.344/16 representou um grande avanço ao enfrentamento do tráfico de pessoas no Brasil, haja vista que estabeleceu diretrizes e 
princípios a serem perseguidos, mecanismos de prevenção e repressão do crime, além de assegurar a proteção e assistência às vítimas.

\section{Exploração sexual: requisitos para configuração do crime e distinção entre exploração sexual e prostituição}

Para Guilherme Nucci, a exploração sexual deve ser caracterizada como forma de retirada de vantagem em relação a alguém, valendo-se de fraude, ardil, posição de superioridade ou qualquer outra forma de opressão (RODRIGUES, 2013).

Para este mesmo autor, a prostituição voluntária não configura exploração sexual, eis que não há fraude ou engodo no proceder do agente.

Com relação a tal entendimento, válido destacar que a prostituição, conquanto seja sabidamente uma atividade antiquíssima, divide entendimentos entre aqueles que a consideram imoral e degradante e os que a veem como um trabalho como qualquer outro, merecendo, inclusive, regulamentação.

Há, portanto, uma diversidade de tratamentos dispensados àqueles que exercem a prostituição, muito embora em todas as vertentes esteja bem presente o preconceito relativo à atividade.

O Brasil adota o sistema abolicionista desde 1942, segundo o qual se pune o proxeneta, o rufião e o traficante de mulheres, mas não a prostituição em si, vez que a prostituta é considerada vítima e exerce a atividade em razão de coação de um terceiro, o agenciador ou explorador, que recebe parte dos lucros obtidos pelo profissional do sexo.

Independentemente do tipo de política criminal adotada nos diversos países, o que se percebe é que a prostituição pode ser enxergada ou como uma forma de exploração sexual ou como um ofício qualquer. Para os que se filiam a esta segunda corrente, a dignidade humana pressupõe autonomia de vontade e a opção pelo exercício de tal atividade deve ser respeitada (RODRIGUES, 2013),

Com relação a isso, acreditamos que seja qual for o entendimento adotado, não podemos esquecer que o direito à liberdade é garantido a todos pelo Estado democrático de direito, portanto, ao nos depararmos com uma situação de consentimento válido, não eivado por qualquer tipo de vício e não se tratando de pessoa vulnerável, a opção laboral pela prostituição deve ser respeitada e regulamentada e não excluída do regramento legal tão somente por uma questão moral.

Portanto, aspectos religiosos ou moralistas não devem estar presentes na legislação penal, não cabendo ao legislador sobrepor a moral social e os bons costumes à liberdade individual, até mesmo porque o bem jurídico tutelado pelo direito penal sexual é a liberdade sexual individual e não a moralidade pública sexual.

$\mathrm{O}$ ponto controvertido entre estes conceitos reside no fato de que sabemos que a maioria das pessoas que recorrem à prostituição, pertencem às classes sociais mais pobres e vulneráveis, o que nos leva a crer que não tiveram opção de escolha, muito embora esta não seja uma verdade absoluta, fazendo-se necessária uma análise mais apurada de cada caso em suas individualidades.

Ainda relativamente ao perfil dos que recorrem à prostituição, pode-se afirmar que conquanto tal atividade não se restrinja ao sexo feminino, à idade adulta nem a um determinado nível socioeconômico, é bem verdade que as mulheres jovens, solteiras e 
vítimas de violência doméstica ou abuso sexual na infância são a maioria e muitas delas vêm de uma posição socioeconômica inferior e com menos oportunidades de estudo e qualificação profissional, isto é, são socialmente vulneráveis.

Quanto aos aliciadores, são geralmente pessoas bastante comunicativas, com grande poder de persuasão, estáveis economicamente (MENDES, 2015).

O que se conclui de tudo o que foi posto, é que há uma linha bastante tênue entre o crime de exploração sexual e a prostituição, sendo importante destacar o que temos o dever de punir e evitar é o crime de exploração sexual, no qual a vítima passa a praticar a prostituição porque foi coagida, ameaçada, enganada ou até mesmo porque estava em uma situação de extrema vulnerabilidade, que não lhe permitia escolher uma opção aceitável a não ser submeter-se ao explorador. Nesse caso, o seu consentimento deve ser considerado viciado, por não corresponder a uma vontade real e a conduta do explorador punida.

\section{O consentimento da vítima: Causa excludente do tráfico para exploração sexual?}

De acordo com o que prevê o Protocolo de Palermo, em seu art. $3^{\circ}$, b, "havendo algum tipo de exploração no destino final, o consentimento dado pela vítima, independente da modalidade, será considerado irrelevante se houver sido obtido mediante ameaça, força, coação, fraude, engano, abuso de autoridade ou situação de vulnerabilidade".

$\mathrm{Da}$ análise do dispositivo, vê-se que quando configurado o crime de tráfico para fins de exploração sexual, o eventual consentimento dado pela vítima é considerado viciado, de modo que deve haver punição do agente.

É importante destacar que o consentimento só será levado em conta quando se tratar de bem jurídico individual, entretanto, no crime de tráfico de pessoas para fins de exploração sexual, o bem jurídico é difuso e coletivo, de modo que o delito não pode ser afastado pela vontade de um só indivíduo.

Melhor explicando, no direito penal sexual, o que se protege é a liberdade sexual, cuja lesão restaria superada caso a vítima consentisse. No caso da dignidade sexual, contudo, o consentimento da vítima não elide a responsabilidade do agente por se tratar de bem indisponível.

Meios de atuação das redes criminosas e as principais rotas do tráfico no Brasil, com maior enfoque na análise da rota de prostituição Venezuela-Roraima:

O crime organizado transnacional (que pode envolver atividades transfronteiras) é uma das mais sérias ameaças à soberania do Estado democrático de Direito e, devido à sua complexidade, existe uma certa dificuldade por parte dos doutrinadores em conceituálo.

$\mathrm{O}$ art. $2^{\mathrm{o}}$ da Convenção das Nações Unidas para o combate ao crime organizado transnacional, definiu grupo organizado criminoso da seguinte forma: “ grupo estruturado de três ou mais pessoas, existente há algum tempo e atuando concertadamente com o propósito de cometer uma ou mais infrações graves ou enunciadas na presente convenção, com a intenção de obter, direta ou indiretamente, um benefício econômico ou outro benefício material” (BRASIL, 2004) 
O tráfico internacional de pessoas insere-se nesse contexto de crimes organizados transnacionais, cuja atuação provoca inúmeras consequências, dentre as quais, o sentimento de ineficiência do Estado e a desordem social, o que acaba por forçar os Estados a se unirem para buscar mecanismos de prevenção e combate a essa forma de criminalidade, afinal a solução do problema não pode ser depositada apenas nas medidas policias, mas, também na criação de políticas públicas que visem à superação das causas profundas do fenômeno.

No que diz respeito ao modo como essas organizações criminosas atuam, vale dizer que os aliciadores do tráfico geralmente se deslocam para países com graves problemas sociais e acentuada pobreza, onde as vítimas são mais vulneráveis.

Vivendo em situações precárias, muitas vezes desempregadas ou trabalhando na informalidade, recebendo baixos salários, tendo filhos para sustentar e/ou famílias para ajudar, essas pessoas, em sua maioria mulheres são facilmente ludibriadas com promessas de trabalho como modelos, dançarinas, garçonetes, baby-sitter e até com propostas de casamentos com homens considerados bem de vida. (apud SALES et al, 2005).

As organizações criminosas providenciam a documentação dessas pessoas (geralmente falsas), oferecem dinheiro para a passagem e, ao chegar ao local de destino, as vítimas descobrem que foram enganadas quanto à atividade que exercerão (de prostituição) e, após serem vendidas a donos de bordéis, os aliciadores passam a cobrá-las os valores despendidos com o seu deslocamento e os que elas gastarão com sua subsistência no local, tais como: hospedagem; comida entre outras despesas, tornando-as "prisioneiras" e mantendo-as em cárcere privado.

Para quem realiza este tipo de exploração, a atividade tem baixos riscos e altos lucros. As mulheres traficadas entram no seu país de destino com visto de turista e a ação da exploração sexual muitas vezes é camuflada nos registros por atividades legais como o agenciamento de modelos, babás, garçonetes ou dançarinas.

Nas redes de tráfico mais complexas, várias são as pessoas envolvidas e que contribuem para que o crime aconteça, havendo desde os aliciadores, como também os transportadores, os servidores públicos corruptos (que providenciam a documentação falsa) e os informantes, que se encarregam de checar as rotinas de fiscalização da imigração.

No que tange ao gênero do traficante, as mulheres têm um importante papel no processo do tráfico de pessoas, a maioria delas são recrutadoras, recepcionistas ou guardacostas das vítimas, principalmente no caso de tráfico para fins de exploração sexual feminina.

Isso porque se entende que há uma maior possibilidade dessas mulheres estreitarem relações com as possíveis vítimas.

Como muitos dos imigrantes vítimas dessas redes criminosas ingressam no país de forma ilegal ou, mesmo que de forma legal, têm os seus passaportes confiscados, tornam-se escravizadas por dívidas e sem possibilidades de retorno ao país de origem, de forma que acabam explorados sexualmente.

Dito isto, resta evidenciado que a restrição das políticas migratórias pode ser citada como um dos incentivos para a formação dessas organizações destinadas a favorecer o ingresso, legal ou ilegal, de migrantes nos países mais cobiçados ou que possam ofertarlhes melhores condições de vida. 
O Brasil possui ao todo, 24I rotas de tráfico humano, sendo que o maior contingente concentra-se nas regiões Norte e Nordeste, contando com 76 e 69 delas, respectivamente.

Essas rotas são dinâmicas, haja vista que os locais de origem e destino do tráfico interno e internacional de pessoas mudam rapidamente, em função das ações de combate ao crime e da criação de novos mercados para exploração, por isso, o mais importante é conhecer o perfil destas rotas, que em geral:

São estrategicamente construídas a partir de cidades próximas a rodovias, portos e aeroportos, oficiais ou clandestinos; saem do interior dos estados em direção aos grandes centros urbanos ou às regiões de fronteira internacional; há fortes indícios de que as rotas internas e internacionais possuem conexões com o crime organizado.

Só em Roraima, estado brasileiro localizado na região Amazônica e que faz fronteira com a República Bolivariana da Venezuela, constituindo-se na principal porta de entrada para imigrantes venezuelanos, houve um sensível aumento do fluxo migratório desde 2015, especificadamente nas cidades de Boa Vista e Pacaraima.

O estado de Roraima faz fronteira com a Venezuela e a República Cooperativista da Guiana, sendo esse trecho considerado como um dos principais para as rotas do tráfico de pessoas para a exploração sexual e outras atividades ilícitas.

Com a pavimentação da BR-174, esses crimes ganharam mais expressão, pois essa BR liga Manaus à Venezuela e facilita a entrada e saída por meio da via terrestre. Ademais, ao longo desse trecho há vilarejos às margens da rodovia que propiciam o comércio sexual, favorecendo desse modo o tráfico de mulheres, pois servem como ponto de parada para os viajantes, os quais aproveitam para descansar e se divertir.

As casas noturnas e prostíbulos que apresentam shows destrip-tease e outros tipos de "entretenimento" são comuns em Pacaraima e em Santa Elena de Uairén que atendem, sobretudo, turistas e caminhoneiros.

Vale asseverar que a fronteira da Venezuela é a preferida pelas quadrilhas de traficantes, pois nela não há controle rígido, então, as mulheres trazidas de Manaus e de Boa Vista atravessam a fronteira de táxi até Santa Elena do Uiarén, por meio da Transmuambeira, que passa por detrás dos postos de fiscalização da receita Federal, da Polícia Federal e do Ministério da Agricultura, sem maiores dificuldades.

Tal facilidade pode ser atribuída ao fato de que é muito comum o envolvimento dos agentes públicos nas redes de tráfico, que normalmente aceitam suborno para deixarem os traficantes passar com suas presas pelas fronteiras.

Podemos afirmar que a fragilidade de fiscalização na fronteira oportuniza essa prática ilícita, tanto no Brasil quanto na Venezuela, haja vista que as polícias federal e rodoviária federal estão mais preocupadas em coibirem o tráfico de drogas, passando despercebido o tráfico de mulheres na fronteira, como se menos importância merecesse.

Essa intensa mobilidade migratória, aliada à falta de condições estruturais do Estado de Roraima para abrigar tais pessoas, além da ausência de fiscalização na fronteira por parte das autoridades policiais, tem contribuído para o aumento do tráfico humano para fins de exploração sexual no local, não havendo políticas públicas efetivas para prevenção e combate da criminalidade.

É importante também que se forneça treinamento aos policiais, agentes de fronteira ou alfandegário dentre outros profissionais para evitar que a vítima de tráfico seja 
revitimizada, sendo apenas deportada sem uma maior análise da situação a que esteve submetida durante sua estada no país.

\section{A Importância da Cooperação Jurídica internacional no combate ao Tráfico Internacional de Pessoas:}

O tráfico internacional de pessoas ocorre dentro ou por meio das fronteiras dos países, por isso, se faz necessária uma estratégia global para que haja redução dos efeitos perversos desse crime sobre as vítimas, uma vez que em se tratando de crime transnacional, que não se processa em um único Estado soberano, não prescinde da cooperação entre os Estados.

Tal cooperação é tida como imprescindível já que a ação estatal isolada é insuficiente para desarticular a ação das organizações criminosas que atuam no tráfico internacional de pessoas, sendo preciso que os Estados cooperem entre si, quer seja por meio de tratados multilaterais e bilaterais, através da solicitação de auxílio direto ou mediante o instituto da extradição.

A cooperação internacional pode ser técnica ou jurídica. A técnica, materializa-se por meio de parcerias entre governos e organismos internacionais que, na maioria das vezes estabelecem acordos de cooperação para combater o tráfico humano de forma mais eficiente.

Por outro lado, a cooperação jurídica internacional se dá pela solicitação formal de um país a outro, de alguma medida judicial, investigativa ou administrativa que seja necessária para um caso concreto que esteja em andamento.

Importante destacar que além de adequar o ordenamento jurídico interno para melhor combater os crimes transnacionais, é também indispensável que haja uma comunicação adequada entre os países envolvidos, o que não importa em desrespeito à soberania de cada nação.

A aproximação entre os Estados favorece o surgimento das Autoridades centrais, que legitimam a sua atuação no plano internacional por meio dos instrumentos de cooperação ratificados pelos países. As autoridades dos diversos países devem trabalhar em conjunto para que haja celeridade na investigação e na obtenção de provas.

Ou seja, com vistas a facilitar a comunicação entre o Estado requerido e o Estado requerente, houve a necessidade de, preferencialmente, centralizar o envio e recebimento de solicitações de cooperação internacional em um único órgão no país, chamado de Autoridade Central, à qual compete receber, analisar, adequar, transmitir e acompanhar o cumprimento dos pedidos de cooperação jurídica das diversas instituições nacionais, observando os marcos normativos internacionais, bem como a legislação e os costumes do país estrangeiro.

\section{Governança migratória em Roraima}

Podemos dizer, em resumo, que a governança migratória no Estado de Roraima é subdividida entre os seguintes atores: governamentais; sociedade civil organizada, terceiro setor e atores globais. 
O Estado Brasileiro vem atuando no estado de Roraima especialmente através do Exército Brasileiro e da Polícia Federal (no controle migratório) e das autoridades locais (governo do estado e municípios) nas questões de ordem social.

Apesar do viés humanitário nas comunicações oficiais, a ações do Brasil pouco tem contado com a participação do Ministério dos direitos humanos, Ministério do trabalho, da saúde e educação, o que tem gerado muitas críticas já que vem se revelando mais atrelada às questões de segurança nacional.

Prova disso foi o lançamento da Operação Acolhida pelo Exército Brasileiro, com o objetivo de apoiar, com pessoal, material e instalações, a montagem de estruturas e a organização das atividades necessárias ao acolhimento de pessoas em situação de vulnerabilidade, decorrente do fluxo migratório para o Estado de Roraima (PEREIRA, MÉRCHER,2018)

Tal operação organiza-se em três eixos: I) ordenamento da fronteiradocumentação, vacinação e operação controlem do Exército Brasileiro;2) acolhimentooferta de abrigo, alimentação e atenção à saúde; 3) interiorização- deslocamento voluntário de migrantes e refugiados venezuelanos de Roraima para outras Unidades da Federação, com objetivo de inclusão socioeconômica.

Para tanto, foi implantado um posto de triagem ao lado da polícia federal e um posto de apoio a migrantes de passagem ao lado do terminal rodoviário de Boa Vista - RR. Este último oferece serviços de guarda de mochilas, consignação de barracas para família dormir durante a noite, chuveiros para banhos e um espaço de apoio para cuidar de crianças enquanto os pais buscam trabalho.

Há também um setor específico da Operação Acolhida voltado para recrutamento laboral e um setor de propaganda. Ou seja, o exército passou a desenvolver funções de assistência social diretamente.

Desta forma, não há como negar que o governo do Estado não tem trabalhado de forma muito assertiva na gestão da crise migratória, eis que busca quase sempre judicializar as questões e transferir a competência ao Governo federal.

O Poder municipal, por sua vez, especialmente na cidade de Boa vista também tem se mostrado muito ausente nas respostas esperadas.

Isso se deve porque, em vez de articular as ações de governo nas esferas federal, estadual e municipal e fortalecer a sociedade civil organizada, o governo federal delegou ao exército a implementação da política migratória, daí porque se diz que há um controle militar do fluxo migratório.

Assim, o que se observa é que por trás do plano emergencial de fluxo migratório apresentado pelo comando militar, revela-se uma estratégia de controle territorial do estado de Roraima e o mapeamento total das ações voltadas para migrantes por parte do serviço de inteligência do exército.

O governo do estado e as prefeituras, em especial, a Prefeitura de Boa Vista (RR) perdeu seu papel estratégico na política migratória, tornando-se atores secundários. (LIMA, 2019)

É certo que a sociedade civil organizada também tem desempenhado um papel de fundamental importância na gestão emergencial da crise, vez que fornece comida, moradia e gêneros de primeira necessidade, muito embora as ações sejam, muitas vezes, desordenadas e desencontradas. 
No terceiro setor destacam-se a Caritas (Confederação de organizações humanitárias da igreja católica), a Diocese de Roraima, o serviço de jesuítas para migrantes e refugiados, os mórmons, a maçonaria a fraternidade sem fronteiras e a fraternidade humanitária. Também não podemos deixar de apontar também a Cruz Vermelha e os médicos sem fronteiras.

O que se conclui de tudo o que foi analisado neste tópico é que a política migratória emergencial desenvolvida pela Operação Acolhida está desarticulada das políticas municipais e estaduais de educação e saúde e ignora o desenvolvimento econômico da região.

Ademais, as suas ações têm caráter emergencial, havendo pouco investimento em ações de caráter estrutural, que possibilitem a construção de uma economia que alavanque a produção regional de bens e serviços úteis e saudáveis. Pelo contrário, já que os altos investimentos empregados no seu desenvolvimento, apenas fortalecem economicamente o exército.

\section{CONCLUSÃO}

A pesquisa objetivou demonstrar que o problema do tráfico internacional de pessoas está diretamente relacionado aos movimentos migratórios, bem como à exclusão social e à falta de oportunidades em países menos desenvolvidos, de modo que para combater este ilícito, a principal ação deve ser a de buscar inserir na sociedade, as vítimas de tal crime, considerando-as titulares de direitos humanos que merecem proteção.

Deve-se também buscar a redução das desigualdades sociais, o que permitiria às pessoas permanecerem em seus locais de origem sem necessidade de buscar condições dignas de vida em outros países. Assim, é fato que não basta o fechamento de fronteiras nem tampouco um maior recrudescimento das leis para enfrentamento da situação.

Faz-se necessário que entendamos que a migração cumpre importantes papéis nas sociedades, tanto exportadoras quanto receptoras, apesar de trazer consigo diversos desafios para os países de acolhida, tais como a pressão nos sistemas públicos, a maior competição no mercado de trabalho e tensões culturais. Assim, cremos que a maior valorização destes aspectos positivos relativos aos fluxos migratórios deve ser o ponto central quando da criação de políticas públicas migratória.

É imperioso também, que os países se conscientizem da sua necessária participação na construção de uma cultura universal de respeito aos direitos humanos, mediante o investimento em planos não meramente conceituais, mas sobretudo operacionais, sendo também fundamental que proteção desses direitos seja integral, englobando os direitos civis mas também os políticos, econômicos, sociais e culturais.

\section{REFERÊNCIAS}

ANNONI, Danielle. O Direito Internacional dos refugiados e o Brasil. Curitiba: Juruá, 2013.

BAUMAN, Zygmunt. Estranhos à nossa porta. Rio de Janeiro: Zahar, 2017. 
BRASIL. Protocolo Adicional à Convenção das Nações Unidas contra o Crimes Organizado Transnacional Relativo à Prevenção, Repressão e Punição do Tráfico de Pessoas, em Especial Mulheres e Crianças. Decreto nํ. 5.017, de I2 de março de 2004.

COSTA, Vitória Volcato da. Direitos Humanos dos imigrantes venezuelanos no Mercosul: A recepção adotada pelos Estados Partes. Belo Horizonte: Arraes editores, 2020.

FREIRE, Sarah Maria Veloso. Tráfico internacional de pessoas e cooperação internacional - Um olhar no Brasil. Rio de Janeiro: Lumen Juris, 2017.

GALINDO, George Rodrigo Bandeira (org). Migrações, deslocamentos e Direitos Humanos I. ed. - Brasília: IBDC; Grupo de Pesquisa C\&DI, 2015.

HIRST, Paul; THOMPSON, Grahame. Globalização em questão: a economia internacional e as possibilidades de governabilidade, 4 ed. Tradução de Wanda Caldeira Brant. Petrópolis: Vozes, 2002.

LIMA, José Carlos Franco de. Visão Panorâmica da Migração Venezuelana em Roraima. Disponível em: https://escola.trtir.jus.br/index.php/noticia-ejud/2052- Acesso em: 15/03/202I.

MARINUCCI, MILESI. Migrações internacionais contemporâneas. Disponível em: http// www.ufjf.br. Acesso em: 14/oI/202I.

MENDES, Afonso. Tráfico de pessoas para fins de exploração sexual: o crime do século XXI. Abr. 2015. Disponível em: <https://jus.com.br/artigos/37821/trafico-de-pessoas-para-finsde-exploracao-sexual-o-crime-do-seculo-xxi>. Acesso em: o9 de fev. 2021.

NASCIMENTO, Luiz Sales do. A cidadania dos Refugiados no Brasil. São Paulo: Ed. Verbatim, 2012;

PEREIRA,Guilherme; MÉRCHER, Leonardo. Crise Humanitária na Venezuela: Como o Brasil tem lidado com o fluxo migratório de venezuelanos. Artigo TCC-2018. Disponível em: https:// repositório.uninter.com. Acesso em I4/04/202I.

PINTO, Eduardo Vera-Cruz; PERAZZOLO, José Rodolpho; BARROSO, Luís Roberto; SILVA, Marco Antonio Marques da; CICCO, Maria Cristina de (coords). Refugiados, Imigrantes e igualdade dos povos - São Paulo: Quartier latin, 2017.

REY

RODRIGUES, Thaís de Camargo. Tráfico internacional de pessoas para exploração sexual. São Paulo: Saraiva, 2013.

SALES, Lília; ALENCAR, Emanuela; RABELO, Cilana; COSTA, Andreia. A questão do consentimento da vítima no Tráfico de seres humanos. Disponível em: https: www.publicadireito.com.br. Acesso em: 08/04/2021. 